\title{
Synergistic Anticancer Potential of Water Garlic Extract and Copper in a Human Hepatocarcinoma Cell Line
}

\author{
Angelo De Martino ${ }^{1}$, Piera Torricelli ${ }^{2}$, Hanan Mahmoud Abu-Zeid ${ }^{3}$, Anna Shevchenko ${ }^{4}$, \\ Alberto Siciliano ${ }^{1}$, Simone Beninati ${ }^{1, *}$ \\ ${ }^{1}$ Department of Biology, University of Rome "Tor Vergata", Rome, Italy \\ ${ }^{2}$ Department SPES, University of Molise, Campobasso, Italy \\ ${ }^{3}$ Faculty of Science, Botany Department, Alexandria University, Alexandria, Egypt \\ ${ }^{4}$ People's Friendship University of Russia, Moscow, Russia
}

Email adress:

beninati@bio.uniroma2.it (S. Beninati)

\section{To cite this article:}

Angelo De Martino, Piera Torricelli, Hanan Mahmoud Abu-Zeid, Anna Shevchenko, Alberto Siciliano, Simone Beninati. Synergistic Anticancer Potential of Water Garlic Extract and Copper in a Human Hepatocarcinoma Cell Line. Cancer Research Journal.

Vol. 4, No. 2, 2016, pp. 28-31. doi: 10.11648/j.crj.20160402.11

\begin{abstract}
Garlic extract in water, supplemented with copper, exerts an enhanced anti-proliferative and a caspase-independent apoptotic activity in a human hepatocarcinoma HepG2 cancer cell line. Furthermore, a DNA double strand break downstream, likely responsible for the observed cell death in HepG2 cell, was evidenced by an early over expression of $\mathrm{p} 53$ and $\mathrm{p} 21$. This observed synergistic antiproliferative and antitumor capability of water garlic extract, in the presence of copper, might be useful as new tool in cancer prevention and therapy.
\end{abstract}

Keywords: Water Garlic Extract, Copper, HepG2, p53, p21, AIF

\section{Introduction}

Although the chemistry of garlic is quite complex, it is well known that this plant contains organosulfur compounds (OSCs) as precursors of the bioactive products [1]. These bioactive products are not present in intact plant, but they are released upon various methods of extraction of garlic in oil or water solvents $[2,3]$. These OSCs may act exerting their effect on various diseases [4]. The antioxidant activity of water garlic extracts (WGEs) may be related to the elevated content in OSCs and selenium compounds [5] but the specific phytocompounds involved in the anti-inflammatory and antineoplastic activities are yet unknown [6]. Garlic and its water extracts have shown a clear medicinal role in humans, like antimicrobial, hypoglycemic, lipid-lowering and anticancer properties [7]. Many sulfur-containing bioactive compounds were identified in garlic over the years, with a protective effect against several types of cancer [8].

Copper $(\mathrm{Cu})$ is required for the catalysis of several enzymes [9] and it is a trace element with physiological functions. WGE in the presence of $\mathrm{Cu}$ (WGE-Cu), has evidenced an enhanced antitumor activity in an in vitro experimental culture of HepG2, human hepatocarcinoma cells. Furthermore, a DNA double strand break downstream, likely responsible for the observed cell death in WGE-Cu-treated HepG2 cells, was confirmed by the over expression of p53 and $\mathrm{p} 21$. These findings give support to the potential use of WGE-Cu for cancer prevention and therapy.

\section{Experimental Protocol}

\subsection{Cell Cultures}

HepG2 cells (ECCC Promochem, UK), were grown in a glutamine-containing RPMI 1640 medium (Sigma, St. Louis, MO) with $1 \%$ sodium pyruvate, $1 \%$ non-essential amino acids, $10 \%$ fetal calf serum, and incubated at $37^{\circ} \mathrm{C}$ in $5 \% \mathrm{CO}_{2}$ in air. Cells were plated at a density of $4 \times 10^{4}$ cells $/ \mathrm{cm}^{2}$.

\subsection{Water Garlic Extracts}

Local garlic producers provided garlic bulbs, harvested from the end of July. Complete steps on preparation of water garlic extracts (WGE) are reported in patent $n^{\circ}$ RM2008A00008 (registered 2008-14-02). WGE was divided 
in aliquots, stored at $-20^{\circ} \mathrm{C}$ and sterilized by a $0.2 \mu \mathrm{m}$ cellulose membrane before use.

\subsection{Cell Treatments}

WGE was thawed just before use and added to the cell medium at several concentrations, together with water solutions of $\mathrm{CuSO}_{4}$ at several concentrations. Concentration of WGE-Cu, was chosen when proved sufficiently cytostatic and less toxic to the cells. HepG2 cancer cells were treated with a final concentration of $1 \%(\mathrm{v} / \mathrm{v}) \mathrm{WGE}$ and $25 \mu \mathrm{mol} / \mathrm{L} \mathrm{Cu}$ (II) sulfate anhydrous $\left(\mathrm{CuSO}_{4}\right)$ dissolved in the culture medium.

\subsection{Cell Viability and Apoptosis}

HepG2 $\left(5.0 \times 10^{5}\right.$ cells $)$ were preincubated in a humidified air environment containing $5 \% \mathrm{CO}_{2}$ at $37^{\circ} \mathrm{C}$ for $30 \mathrm{~min}$. After preincubation, $1.0 \times 10^{5}$ cells were placed in $5 \mathrm{~mL}$ round-bottom tubes and incubated with $190 \mu \mathrm{L} 0.2 \%$ trypan blue (TB) solution diluted in PBS to perform the TB exclusion test with counting in a Neubauer chamber. Apoptotic cells were detected by using a FITC Annexin V apoptosis detection kit 1 (BD Pharmingen, San Diego, CA, USA).

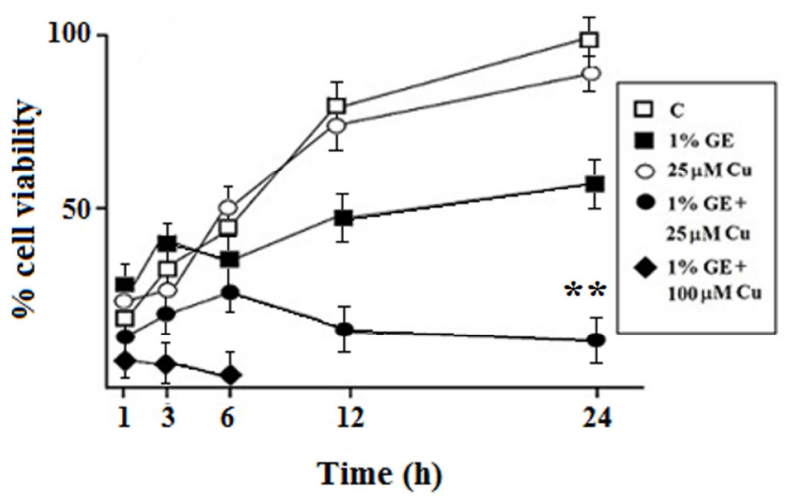

Figure 1. Effects of WGE-Cu treatments on HepG2 hepatoma cells viability. HepG2 cells were incubated with 1\% (v/v) WGE and Cu $25 \mu \mathrm{mol} / \mathrm{L}$ or 100 $\mu \mathrm{mol} / \mathrm{L}$ at different times. Viability was evaluated by trypan blue exclusion test with counting in a Neubauer chamber. Data are expressed as means $\pm S$. D. $* * p<0.05(n=6)$.

Briefly, after treatment with various concentrations of WGE- $\mathrm{Cu}$, at $1,3,6,12$ and $24 \mathrm{~h}$, cells were collected and washed with PBS, resuspended in a binding buffer, and stained with Annexin V-FITC and propidium iodide (PI) for $15 \mathrm{~min}$ at room temperature in the dark, prior to the addition of binding buffer. Flow cytometry analyses were performed with Cytomics FC 500 (Beckman Coulter, Brea, CA, 1622686 USA). In each sample, 10,000 cells were sorted. The data were analyzed by using CXP Software (Beckman Coulter, Inc., Fullerton, CA, USA).

\subsection{Western Blot Analyses}

Cell pellet was resuspended in a lysis buffer containing 10 $\mathrm{mmol} / \mathrm{L}$ Tris-HCl, pH 7.4, $5 \mathrm{mmol} / \mathrm{L}$ EDTA, $150 \mathrm{mmol} / \mathrm{L}$ $\mathrm{NaCl}, 0.5 \%$ IGEPAL CA-630 and protease inhibitors (Sigma Aldrich, USA). After $30 \mathrm{~min}$ incubation in an ice-bath, cells were disrupted by $10 \mathrm{~s}$ sonication. Lysates were then centrifuged at $14,000 \times g$ for $15 \mathrm{~min}$ at $4^{\circ} \mathrm{C}$ and supernatants were removed and stored at $-80^{\circ} \mathrm{C}$. For p 53 and p 21 detection, $20 \mu \mathrm{g}$ of proteins were loaded on $10 \%$ polyacrylamide gel and transferred onto a nitrocellulose membrane (Bio-Rad, Hercules, CA). Polyclonal anti-p21 (1:5000) (UCSS, Billerica, MA, USA); monoclonal anti-p53 (1:5000) and monoclonal anti-catalase (1:2500) (UCS Diagnostic, Italy), were used as primary antibodies. The specific protein complex formed upon appropriate secondary antibody (Bio-Rad) treatment (1:10000) was identified using a FluorChem imaging system (Alpha Innotech - Analitica De Mori, Milano, Italy) after incubation with ChemiGlow chemiluminescence substrate (Alpha Innotech). Proteins were determined according to the method of Lowry et al. [10]

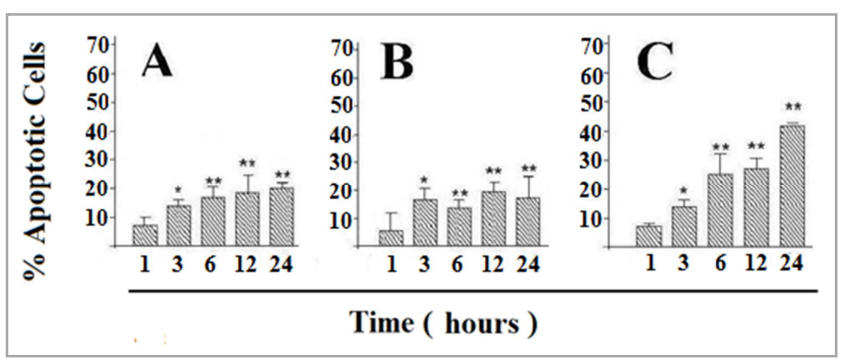

Figure 2. WGE-Cu treatment induces apoptosis in HepG2 cancer cell. Hep 2 cells were treated with $1 \%(v / v) W G E-C u 25 \mu \mathrm{mol} / \mathrm{L}$ at different times. (A) HepG2 cells incubated with $1 \%$ WGE; (B) Hep G2 cells incubated with 25 $\mathrm{mmol} / \mathrm{L} \mathrm{Cu}$; (C) HepG2 cells incubated with 1\% WGE-Cu $25 \mu \mathrm{mol} / \mathrm{L}$. Data are expressed as means $\pm S$. D. * $p<0.05 ; * * p<0.001(n=4)$.

\subsection{Statistical Analysis}

The results were presented as the mean values \pm SDs of three independent experiments. Student's $t$ test was used for comparisons between two groups, and an ANOVA with a post hoc test was used for multiple comparisons. These statistical analyses were performed using SPSS software, version 16.0 (IBM Corp., Armonk, NY, USA). The value indicating significant differences was set at $p<0.05$.

\section{Results}

\subsection{Viability of WGE-Cu-Treated HepG2 Hepatoma Cells}

A HepG2 cell medium with final concentration of 25 $\mu \mathrm{mol} / \mathrm{L} \mathrm{Cu}$, together with $1 \%(\mathrm{v} / \mathrm{v})$ WGE, showed a remarkable cytostatic activity at $6 \mathrm{~h}$ of incubation respect to the control (Figure 1). On the contrary, an evident cytotoxic activity was observed keeping WGE at $1 \%$, but with higher concentration of $\mathrm{Cu}(100 \mu \mathrm{mol} / \mathrm{L})$. A cell viability decrease of $79 \%$ was observed in WGE (1\%)-Cu(25 $\mu \mathrm{mol} / \mathrm{L})$-treated HepG2 after $12 \mathrm{~h}$ of incubation, reaching a value of $86 \%$ reduction at $24 \mathrm{~h}$ of treatment (Figure 1).

\subsection{Apoptosis of HepG2 Cells by WGE-Cu Treatment}

In order to determine whether $1 \% \mathrm{WGE}-25 \mu \mathrm{mol} / \mathrm{L} \mathrm{Cu}$ induced apoptosis in HepG2 cells, we used flow cytometry with a FITC Annexin V apoptosis detection kit 1. The 
results showed that after $1 \% \mathrm{WGE}-25 \mu \mathrm{mol} / \mathrm{L} \mathrm{Cu}$ treatment for $6 \mathrm{~h}$, the percentage of early and late apoptosis in cancer cells was significantly higher (Figure 3C) than that in the control (data not shown) and $1 \%$ WGE- or $25 \mu \mathrm{mol} / \mathrm{L}$ $\mathrm{Cu}$-treated cells (Figures $2 A$ and $B$ ). The percentage of apoptosis reaches a $45 \%$ value upon $24 \mathrm{~h}$ of incubation with WGE-Cu. The results were consistent with the change in number and viability of treated HepG2 cells reported in Figure 1.

\subsection{WGE-Cu Modulates DNA Damage-Related Proteins of HepG2 Cells}

Figure 3 shows the result of Western blot analysis of the expression of $\mathrm{p} 53$, observed upon WGE-Cu treatment of HepG2 cells. High level of expression of p53 normally responds to DNA damage and activates cell cycle arrest and apoptosis. As shown in Figure 3, HepG2 cell treated with 1\% WGE-25 $\mu \mathrm{mol} / \mathrm{L} \mathrm{Cu}$ at several times, had a p53 immunoreactive band rapidly increased already at $30 \mathrm{~min}$, and remained over expressed until $24 \mathrm{~h}$ of treatment. In order to collect more evidences on the possibility that cell death of HepG2 cells is induced by WGE-Cu treatment, we analyzed the expression levels of a cyclin dependent kinase inhibitor, p21, the p53 downstream factor. Figure 3 shows a similar trend of induction of $\mathrm{p} 21$, as previously observed for $\mathrm{p} 53$.

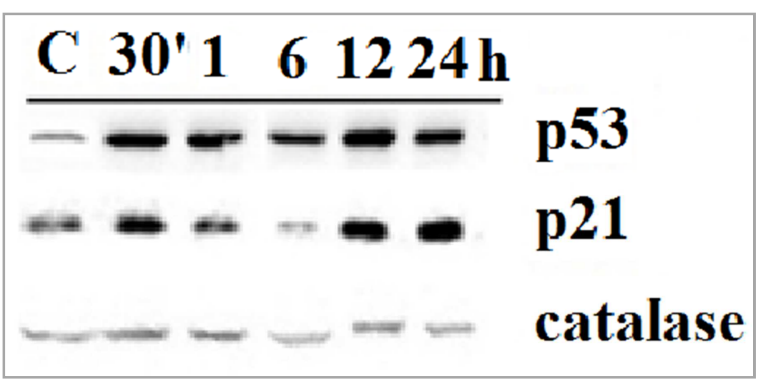

Figure 3. WGE-Cu treatment induces expression of DNA damage-related proteins, p53 and p21. HepG2 were treated with $1 \%$ (v/v) WGE-Cu $25 \mu \mathrm{mol} / \mathrm{L}$ at several times. Lysate proteins of untreated HepG2 cells were used as a control $(\boldsymbol{C})$. Catalase was used as loading control. Immunoblots are from one experiment representative of three that gave similar results.

\subsection{WGE-Cu Modulates Nuclear Translocation of AIF in HepG2 Cells}

Apoptosis inducing factor (AIF) has been proposed to act as a putative reactive oxygen species scavenger in mitochondria. When apoptotic cell death is triggered, AIF translocates to the nucleus, where it leads to nuclear chromatin condensation and large-scale DNA fragmentation which result in caspase-independent HepG2 death [11]. We performed this study to investigate the possibility that, AIF induced death could be a cause of WGE-Cu treatment of HepG2 cells. We have found that AIF immunoreactivity was increased in nuclear fractions of WGE-Cu-treated HepG2 cells at the early stage of treatment (Figure 4). The results of this study imply the existence of a caspase-independent apoptosis occurring under our experimental conditions.

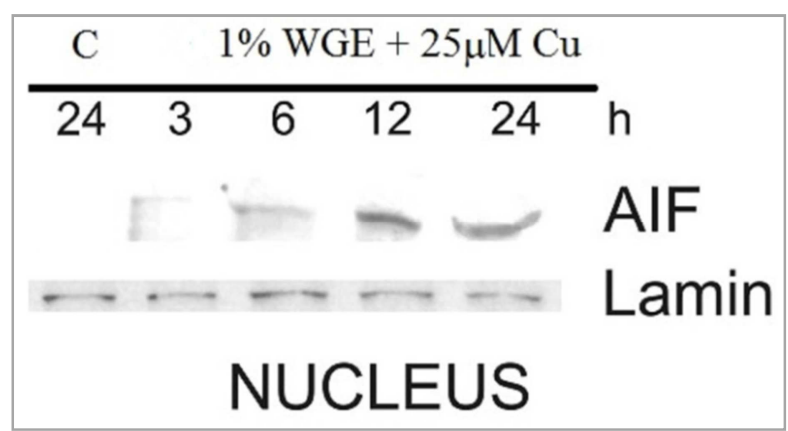

Figure 4. WGE-Cu treatment induces nuclear translocation of AIF. Western blot analyses of apoptosis inducing factor (AIF) translocated in the nuclear compartment as soon as after $6 \mathrm{~h}$ of treatment with $1 \%(\mathrm{v} / \mathrm{v})$ WGE-Cu 25 $\mu \mathrm{mol} / \mathrm{L}$ at several times, suggesting the existence of a caspase-independent apoptosis occurring under our experimental conditions.. Nucleus lysate proteins of untreated Hep 22 cells were used as a control (C). Lamin was used as loading control. Immunoblots are from one experiment representative of three that gave similar results.

\section{Discussion}

A recent increase in the popularity of alternative medicine and natural products has renewed interest in garlic and their derivatives as potential natural remedies. The anticancer effect of garlic is mainly associated with its OSCs [12]. OSCs can inhibit cell-cycle progression, DNA adduct formation and angiogenesis, inducing apoptosis and histone modification [13]. Oxidative stress represents an uncontrolled generation of ROS in the cells with a number of damages to biological macromolecules with consequent diseases. Several molecules introduced with the diet, directly participate to counteract oxidative damages providing a protection to the organism.

The role of foods and dietary phytochemicals in prevention and treatments of cancer has been extensively discussed [14]. At high concentrations, phytochemicals present in WGE may act as pro-oxidants showing a pro-apoptotic action [15]. For the water-soluble constituents of WGE such as S-allylcysteine (SAC) and S-allyl mercaptocysteine (SAMC), limited experimental studies also suggested that both water-soluble compounds can suppress cancer risk and alter the biological behaviors of various human tumors such as breast, prostate, bladder and colorectal cancers [16-19].

We report in this work that a relatively low concentration of WGE $(1 \% \mathrm{v} / \mathrm{v})$ supplemented with $\mathrm{Cu}(25 \mu \mathrm{mol} / \mathrm{L})$ enhances arrest of cell proliferation and induction of a caspaseindependent apoptosis. It appears that the combined WGE-Cu treatment causes a remarkable cell death through a synergistic and specific action of the WGE with $\mathrm{Cu}$, in HepG2 carcinoma cell line. A possible DNA double strand break downstream likely responsible for the observed cell death in HepG2 cell, was evidenced by the increased expression of p53 and p 21 in WGE-Cu-treated HepG 2 cells. It is well known that p53 plays a critical role in the induction of apoptosis, autophagy and cell cycle arrest and stimulated the transcription of different genes including p21, which is one of the cyclin-dependent kinase (CDK) inhibitors. The induction of p21 resultes in CDK inhibition and cell cycle arrest, preventing the replication of damaged DNA [20]. 
These findings support the continued investigation of OSCs as alternative agents in the chemoprevention and chemotherapy of cancer.

\section{Conclusions}

Current conventional chemotherapy treatments are very expensive, toxic and less effective in the majority cancer treatment. Plant-derived active components have been gaining more attention for their anticancer activities. Over the last 25 years, many anticancer drugs introduced are natural products or can be traced back to a natural product source. Many different health benefits have been ascribed to garlic for its diverse OSCs, and the anticarcinogenic actions of garlic have been reported by numerous epidemiological, clinical and preclinical studies. At the same time, the use of garlic as the complementary and alternative medicine (CAM) by patients who are diagnosed with cancers is increasing. The evidences reported in our work provide additional support to the possibility that a combination of WGE and $\mathrm{Cu}$, could have a potential application in the treatment of various type of cancer.

\section{Author Contributions}

Angelo De Martino proposed the project and carried out most of the biochemical experiments; Alberto Siciliano and Anna Shevchenko carried out most parts of the experiments; Piera Torricelli responsible of molecular biology data; Hannan Mahmoud Abu-Zeid contributed to botanical data analysis and interpretation; Simone Beninati contributed to concept, acquisition, interpretation of data and revision of the manuscript.

\section{References}

[1] LD. Lawson, BG. Hughes. Characterization of the formation of allicin and other thiosulfinates from garlic. Planta Med. 1992; 58: $345-350$.

[2] GR. Fenwick, AB. Hanley. The genus Allium. Part 2. Crit Rev Food Sci Nutr. 1985; 22: 273-377.

[3] GR. Fenwick, AB. Hanley. The genus Allium-Part 1. Crit Rev Food Sci Nutr. 1985; 22: 199-271.

[4] H. Amagase, EM. Schaffer, JA. Milner. Dietary components modify the ability of garlic to suppress 7, 12-dimethylbenz(a)anthracene-induced mammary DNA adducts. J Nutr. 1996; 126: 817-824.

[5] SM. Bird, H. Ge, PC. Uden, et al. High-performance liquid chromatography of seleno amino acids and organo selenium compounds. Speciation by inductively coupled plasma mass spectrometry. J Chromatogr A. 1997; 789: 349-359.
[6] E. Dumont, Y. Ogra, F. Vanhaecke, et al. Liquid chromatography-mass spectrometry (LC-MS): a powerful combination for selenium speciation in garlic (Allium sativum). Anal Bioanal Chem. 2006; 384: 1196-1206.

[7] M Bagul, S Kakumanu, TA Wilson. Crude Garlic Extract Inhibits Cell Proliferation and Induces Cell Cycle Arrest and Apoptosis of Cancer Cells In Vitro. J Med Food. 2015; 18(7): 731-737.

[8] E. De Gianni, C Fimognari. Anticancer Mechanism of Sulfur-Containing Compounds. Enzymes. 2015; 37: 167-192.

[9] R. Uauy, M. Olivares, M. Gonzalez. Essentiality of copper in humans. Am J Clin Nutr. 1998; 67: 952S-959S.

[10] OH. Lowry, NJ. Rosebrough, AL. Farr, et al. Protein measurement with the Folin phenol reagent. J Biol Chem. 1951; 193: $265-275$.

[11] E. Hangen, K. Blomgren, P, Bénit, G. Kroemer G, N. Modjtahedi. Life with or without AIF. Trends Biochem. 2010; Sci. 35 (5): 278-287.

[12] LM. Knowles, JA. Milner. Possible mechanism by which allyl sulfides suppress neoplastic cell proliferation. J Nutr. 2001; 131(3s): 1061S-1066S.

[13] N. Druesne-Pecollo, P. Latino-Martel. Modulation of histone acetylation by garlic sulfur compounds. Anticancer Agents Med Chem. 2011; (3) 254-259.

[14] J. P. Kelly, DW. Kaufman, K. Kelley, et al. Recent trends in use of herbal and other natural products. Arch Intern Med. 2005; 165: 281-286.

[15] JY. Yan, FM. Tian, WN. Hu, et al. Apoptosis of human gastric cancer cells line SGC 7901 induced by garlic-derived compound S-allylmercaptocysteine (SAMC). Eur Rev Med Pharmacol Sci. 2013; 17(6): 745-751.

[16] EW. Howard, MT. Ling, CW. Chua, et al. Garlic-derived S-allylmercaptocysteine is a novel in vivo antimetastatic agent for androgen-independent prostate cancer. Clin Cancer Res. 2007; 13(6): 1847-1856.

[17] H. Hu, XP. Zhang, YL. Wang, et al. Identification of a novel function of Id-1 in mediating the anticancer responses of SAMC, a water-soluble garlic derivative, in human bladder cancer cells. Mol Med Rep. 2011; 4(1): 9-16.

[18] D. Liang, Y. Qin, W. Zhao, et al. S-allylmercaptocysteine effectively inhibits the proliferation of colorectal cancer cells under in vitro and in vivo conditions. Cancer let. 2011; 310(1): 69-76.

[19] G. Sigounas, J. Hooker, A. Anagnostou, et al. S-allylmercaptocysteine inhibits cell proliferation and reduces the viability of erythroleukemia, breast, and prostate cancer cell lines. Nutr Cancer. 1997; 27(2): 186-191.

[20] K. Vermeulen, DR. Van Bockstaele, ZN. Berneman. The cell cycle: a review of regulation, deregulation and therapeutic targets in cancer. Cell Prolif. 2003; 36(3): 131-149. 